\title{
Type 1 Diabetes Versus Type 2 Diabetes/Metabolic Syndrome, Opposite Extremes of an Immune Spectrum Disorder Induced by Vaccines
}

\author{
John Barthelow Classen*
}

Classen Immunotherapies Inc., 6517 Montrose Avenue, Baltimore, MD 21212, USA

\begin{abstract}
There is an epidemic in children of type 2 diabetes and metabolic syndrome including individual diseases that form the components of metabolic syndrome. The epidemic resembles the epidemic of type 1 diabetes in children which has been linked to immunization. The epidemic of obesity in US children has a statistically significant positive correlation with the number of vaccine doses recommended. There is a similar trend with both hypertension and metabolic syndrome. The incidence of type 2 diabetes in Japanese children decreased significantly following the discontinuation of the BCG vaccine, a vaccine which is associated with an increased risk of type 1 diabetes. This paper describes two aberrant responses to immunization. At one extreme immunization leads to progressive autoimmune diseases including type 1 diabetes. A second response to immunization, and an opposite extreme to autoimmunity, is for the body to suppress the immune system through increased cortisol activity and other counter measures leading to type 2 diabetes and metabolic syndrome. Some vaccine recipients may have a mixed response, falling between the extremes, such as an incomplete autoimmune disorder or an intermittent autoimmune disorder. The propensity to develop a particular response relates to race. Japanese children produce large amounts of cortisol following immunization and have lower risk of type 1 diabetes but higher risk of type 2 diabetes than White children. Analysis using Austin Bradford-Hill criteria for causation support a causal relation between immunization and metabolic syndrome. Additional studies are needed to further characterize this risk.
\end{abstract}

Keywords: Vaccines, type 1 diabetes, type 2 diabetes, metabolic syndrome.

\section{BACKGROUND}

There is an epidemic of several diseases in human children and adults including hypertension, obesity, hyperlipidemia, low high density lipoprotein [HDL] cholesterol, microalbuminurea, and insulin resistance $[1,2]$. This syndrome has been collectively classified as metabolic syndrome [3] and is closely associated with type 2 diabetes [4] and other health problems including death [5]. Many have blamed poor diet [6] and lack of exercise for the epidemics of type 2 diabetes and metabolic syndrome. Diet and exercise have been touted as the cure for metabolic syndrome but have not been very effective [7] and have not stopped the epidemic to date. The poor diet and exercise theory does not explain the obesity epidemic in children under 6 month of age who don't drink many sodas, don't eat a lot of fried potatoes and have never been very active. Recent data from a Massachusetts health maintance organization [HMO] shows a $73 \%$ increase in overweight infants under 6 months of age from 1980 to 2001 [8].

Several investigators have proposed that metabolic syndrome is an inflammatory condition or the result of increased cortisol production, a hormone that suppresses inflammatory conditions. The epidemic of metabolic syndrome in children mirrors an epidemic of type 1 diabetes in children, which has

*Address correspondence to this author at the Classen Immunotherapies Inc., 6517 Montrose Avenue, Baltimore, MD 21212, USA; Tel: (410) 3778526; E-mail: Classen@vaccines.net been linked to a class of immune stimulants, vaccines [9-12]. A proposed mechanism of vaccine induced metabolic syndrome is presented. Epidemiological evidence supporting an association between immunization and metabolic syndrome is presented. Epidemiological and experimental data are reviewed supporting a racial basis for determining whether an individual is more likely to develop an autoimmune disease like type 1 diabetes or metabolic disease as a complication of immunization.

\section{PROPOSED MECHANISM OF VACCINE IN- DUCED METABOLIC SYNDROME}

\section{A. Autoimmunity and Metabolic Syndrome are Opposing Ends of an Immune Spectrum Disorder}

The proposed mechanism of immunization induced metabolic syndrome is by an intrinsic neuroendrocrine feedback loop to suppress an immune system chronically activated by immunization. It is well accepted that in all organ systems there are homeostatic mechanisms to regulate their activity. Autoimmune diseases are conditions that result from an over active immune system. Likewise one would expect that there would be one or more diseases that arise when the body attempts to suppress what it interprets as an over active immune system. Cortisol is a hormone that suppresses the immune system and can prevent autoimmunity. Hypersecretion of cortisol however can lead to Cushingoid Syndrome which closely resembles metabolic syndrome. Vaccines have been shown to cause autoimmune diseases including type 1 diabetes [9-12] and other chronic inflamma- 
tory conditions [13]. Vaccines are also known to cause cortisol secretion [14-21].

\section{B. Inflammation as the Cause of Metabolic Syndrome}

It has been proposed that metabolic syndrome is an inflammatory condition [22]. This belief is supported by studies have shown that inflammation predates metabolic syndrome [23, 24]. A study on Finnish middle age men [23] found men with elevated C-reactive protein [CRP] concentrations had higher age-adjusted risk of developing metabolic syndrome. A study of men and women in Mexico [24] found women with elevated CRP in the highest tertile had an increased relative risk of developing metabolic syndrome.

Some have suggested that metabolic syndrome causes inflammation [25]. While metabolic syndrome may cause inflammation it is more likely that inflammation initially causes metabolic syndrome. Inflammation has been associated with the development of components of metabolic syndrome, independent of the presence of characteristics of metabolic syndrome $[23,24]$. Glucose intolerance/type 2 diabetes [26] and hypertension [27, 28] are both independently associated with inflammation. There is additional evidence that once metabolic syndrome begins it causes more inflammation [25] which in turn makes the disease worse. Adiposites and the accompanying macrophages appear to make inflammatory mediators. While there is an association between obesity and inflammation [29], obesity can exist without inflammation as demonstrated by obese individuals with a healthy metabolic profile [30]. The later evidence supports the view that in many inflammation precedes the development of metabolic syndrome.

Metabolic syndrome has a remarkable similarity to mild Cushingoid Syndrome [31,32] and several have suggested that metabolic syndrome is caused by increased cortisol activity [33-35]. There is data showing increased cortisol levels associated with metabolic syndrome [36]. There is evidence that increased peripheral activation of cortisol secondary to increased enzymatic activity of 11-beta hydroxysteroid dehydrogenase type 1 contributes to the development of metabolic syndrome [37, 38]. Some have also suggested that metabolic syndrome is in part due to increased cellular uptake of cortisol [39]. Excessive amounts of exogenous glucocorticoids are known to cause hypertension, obesity, hyperlipidemia, and glucose intolerance. The effect is dose dependent. There are many similarities between excessive cortisol activity and metabolic syndrome. Excessive cortisol activity is associated with metabolic disturbances including increased glucose levels, obesity and hyperlipidemia [40] just like in metabolic syndrome. Excessive cortisol activity is also associated with increased cardiovascular events [41, 42] just like metabolic syndrome.

There is biological evidence that specific lymphokines released during inflammation can cause the release of cortisol and cause the biological changes that occur in metabolic syndrome. It has been hypothesized [43] that the metabolic syndrome like responses to lymphokines provide a short term survival advantage helping the host survive noxious events. Hyperlipidemia for example may help the body clear fat soluble toxins. A problem arises in certain individuals when inflammation becomes chronic and the changes lead to metabolic syndrome. In these cases changes that are a survival advantage acutely are chronically an hazard.

\section{Vaccines as an Inducer of Metabolic Syndrome}

Vaccines have been shown to stimulate the immune system in the short term causing the release of cytokines that can increase cortisol activity. The acellular diphtheria tetanus pertussis vaccine has been reported to cause the release of IL-6 [44]. The Diptheria-Tetanus-Polio-Typhim vaccine stimulated IL-6 production [45]. The Diptheria-Tetanuswhole cell Pertussis but not the Diptheria-Tetanus- acellular Pertussis vaccine elicited increased IL-6 at 2 days post immunization [46]. The influenza vaccine stimulated release of IL-6 and IL-10 [47]. The influenza and pneumococcal vaccine caused rises in CRP [48]. Researchers in France have linked aluminum adjuvants in vaccines to an inflammatory condition called myofascititis [13,49]. Several papers have shown that immunization of children can increase cortisol levels at least in the short term [14-21].

Cytokine production, particularly IL-6, increases with age [50-52] and this can explain the increase in metabolic syndrome with age. Both IL-1 [53,54] and IL-6 [55-57] enhance cortisol release and thus have the potential to cause metabolic syndrome. IL-6 has been associated with the development of metabolic syndrome [58, 59]. In addition IL-6 has been directly associated with the development of diabetes [26], insulin resistance [60] and altered lipid levels [6163].

\section{Resetting the Hypothalamus}

A second mechanism by which immunization may lead to the induction of metabolic syndrome is through the resetting of the hypothalamus. Immunization in the first year of life may affect the onset of metabolic syndrome by resetting of the hypothalamus, creating more cortisol release. Two well characterized examples support this hypothesis. It has been shown that the hypothalamus is reset in children who undergo stress in utero. These children produce higher cortisol release and hence have increased symptoms resembling metabolic syndrome [64-66]. A second example of reseting the hypopthalamus is in children which are born with low birth weight and are at increased risk of developing metabolic syndrome [67].

\section{EPIDEMIOLOGY OF VACCINE INDUCED TYPE 2 DIABETES AND METABOLIC SYNDROME}

Epidemiological data support the proposed mechanism of vaccine induced type 2 diabetes and metabolic syndrome.

\section{A. Epidemic of Type 2 Diabetes and Metabolic Syndrome Resembles the Epidemic of Type 1 Diabetes}

One line of support for the proposed mechanism of vaccine induced metabolic syndrome is that the epidemic of metabolic syndrome and type 2 diabetes resembles the epidemic of type 1 diabetes. The role of vaccines in causing the epidemic of type 1 diabetes is supported by data from a prospective clinical trial, animal toxicity data as well as epidemiological data [9-12]. There is an epidemic of metabolic syndrome and its components in children living in the US [1, $2]$ and other countries including the UK and Australia [68, 
69]. Data on the prevalence of metabolic syndrome, obesity, and hypertension in US children has been published covering a period of at least 10 years. Obesity in US children aged 4 to 12 years old increased on average of $3.23-5.85 \%$ per year, depending on race, from 1986 to 1998 in the National Longitudinal Survey of Youths [70]. The prevalence of overweight children increased on average of $1.41 \%$ to $3.60 \%$ per year, depending on race, in the same age group. Similar rises were seen in children age 0-19 years old in the NHANES study [71, 72]. Between 1988 and 2000 the prevalence of obesity rose $4.4 \%$ per year in children age $12-19$ years old, $3.4 \%$ year in children age 6-11 years old, and $4.2 \%$ per year in children age 2-5 years old. Blood pressure also rose in children and adolescents between 1988 to 2000 [73] [ $<<0.001]$. Metabolic syndrome increased on average of $4 \%$ a year in adolescents aged 12-19 years old according to US NHANES data from 1988-1992 to 1999-2000 [2] [p<0.001]. In comparison Type 1 diabetes in children increased $2.3 \%$ per year in the US from 1978-2004 [74].

The findings do not appear to be limited to the US. Data from Finnish children [75] shows the prevalence of obesity in children age 12-18 in the years 1977 to 1999 increased from $1.1 \%$ to $2.7 \%$ in boys [relative risk 2.45 ] and from 0.4

Table 1. Coorelation Between Vaccine Doses and Obesity, Metabolic Syndrome and Diastolic Blood Pressure

\begin{tabular}{|c|c|c|c|c|c|c|}
\hline \multirow{2}{*}{ YEAR } & Vaccine & \multirow{2}{*}{ \% Metabolic Syndrome } & $\%$ with Increased & \multirow{2}{*}{ \% Obese Age 12-19 } & \multirow{2}{*}{ \% Obese Age 6-11 } & \multirow{2}{*}{$\%$ Obese Age 2-5 } \\
\hline & DOSES & & Diastolic Blood Pressue & & & \\
\hline 1978 & 24 & & & 4.8 & 6 & 5 \\
\hline 1979 & 24 & & & & & \\
\hline 1980 & 24 & & & & & \\
\hline 1981 & 24 & & & & & \\
\hline 1982 & 24 & & & & & \\
\hline 1983 & 24 & & & & & \\
\hline 1984 & 24 & & & & & \\
\hline 1985 & 24 & & & & & \\
\hline 1986 & 24 & & & & & \\
\hline 1987 & 24 & & & & & \\
\hline 1988 & 24 & & & & & \\
\hline 1989 & 27 & & & & & \\
\hline 1990 & 27 & & & & & \\
\hline 1991 & 30 & 4.2 & 58.4 & 10.6 & 10.6 & 7.2 \\
\hline 1992 & 34 & & & & & \\
\hline 1993 & 34 & & & & & \\
\hline 1994 & 34 & & & & & \\
\hline 1995 & 34 & & & & & \\
\hline 1996 & 35 & & & & & \\
\hline 1997 & 35 & & & & & \\
\hline 1998 & 35 & & & & & \\
\hline 1999 & 36 & 6.4 & 61.7 & 15.5 & 15.3 & 10.4 \\
\hline 2000 & 39 & & & & & \\
\hline 2001 & 39 & & & & & \\
\hline 2002 & 39 & & & & & \\
\hline 2003 & 41 & & & & & \\
\hline 2004 & 41 & & & & & \\
\hline 2005 & 41 & & & & & \\
\hline \multirow[t]{2}{*}{2006} & 45 & & & & & \\
\hline & & & & $\mathrm{P}<0.05$ & $\mathrm{P}<0.05$ & $\mathrm{P}<0.05$ \\
\hline
\end{tabular}

The number of doses of vaccines recommended for children in the US increased from 24 to 45 in the years 1978 to 2006 . The rise in the number of doses is statistically associated with the increase in obesity in US children age 2-19. A similar but not statistically significant association is also seen in the US with metabolic syndrome and diastolic blood pressure in children. 
to $1.4 \%$ in girls [relative risk 3.5 ]; on average a $5 \%$ rise per year. The prevalence of overweight increased from $7.2 \%$ to $16.7 \%$ in boys and $4.0 \%$ to $9.8 \%$ in girls, on average a $4 \%$ rise per year. During this time the combined measles mumps rubella and hemophilus vaccines were added to the immunization schedule as well as an more potent pertussis vaccine [10]. This increase in obesity is very similar to the $3.4 \%$ per year increase in type 1 diabetes from 1965 to 1996 [76] which has been attributed to an increase in number of vaccines $[10,11]$.

\section{B. Positive Correlation Between the Number of Doses of Vaccine Administered and the Prevalence of Obesity}

There is an association between the number of vaccine doses recommended for US children and rises in obesity and metabolic syndrome. The number of pediatric vaccines universally recommended in the US by the Centers for Disease Control and Prevention [CDC] has increased from seven to thirteen and the number of recommended doses from 24 to 45. There was a statistically significant correlation between the number of doses of vaccine given and obesity in children age 2-5, 6-11 and 12-19 (Table 1). Statistics were performed using the program Statistica, Stat Soft, 1993. The Pearson Product-Moment Correlation module was used to determine the statistical association between number of vaccines doses recommended with obesity. Data on US rates of metabolic syndrome and hypertension in children exists for only two periods of time, two data points, so statistical correlations can not be calculated. However there was a similar trend with both of these outcomes and both outcomes showed a statistically significant rises during the study period. There was a similar trend in Finland with a positive correlation between the number of vaccine doses given and an increased prevalence of obesity, just like in the US [10, 11].

\section{Decline in Type 2 Diabetes Occurred Following Dis- continuation of the Tuberculosis Vaccine [BCG]}

The rates of Type 2 diabetes and metabolic syndrome is increasing throughout the world [77]. However, there was a statistically significant drop in the incidence of Type 2 diabetes in Tokyo Japan in elementary and junior high school students $[78,79]$. The drop occurred in 2003 after the discontinuation of routine BCG vaccination of elementary and junior high school students in Japan [80]. BCG vaccination has previously been associated with an increased risk of type 1 diabetes [9].

\section{Racial Predisposition for Development of Type 1 or Type 2 Diabetes and the Association with Cortisol Secre- tion Following Immunization}

The proposed mechanism that some respond to immunization by developing autoimmune disease while others respond to immunization by developing metabolic syndrome is supported by racial differences in the rates of type 1 and type 2 diabetes and cortisol secretion following immunization. Type 1 diabetes is an autoimmune disease while type 2 diabetes is related to insulin resistance, a component of metabolic syndrome. Type 2 diabetes is associated with obesity, another component of metabolic syndrome, while type 1 diabetes is not. White children including adolescents tend to have an high absolute incidence of type 1 diabetes and a high ratios of the incidence of type 1/type 2 diabetes compared children of Japanese or Chinese decent. The later children have higher incidences of type 2 diabetes and, consequently, a lower ratio of the incidence of type 1 to type 2 diabetes [78, 81-83].

The racial differences in the incidence of type 1 and type 2 diabetes can be explained by cortisol release following immunization. Japanese children have a higher cortisol responses to immunization than White children [84]. The differences in cortisol responses of Whites and Japanese appears to extend into adulthood as well [85]. Because they release more cortisol following immunization, Japanese children would be expected to have a lower rate of autoimmune diseases including type 1 diabetes as well as a lower ratio of type 1/type 2 diabetes compared to Caucasians. Elevated cortisol secretion can cause metabolic syndrome, as described above, but cortisol is an immune suppressant and prevents autoimmune disease. Decreases in cortisol following adrenalectomy leads to increased rates of type 1 diabetes in mice [86] and experimental autoimmune diseases [87, 88].

\section{AUSTIN BRADFORD-HILL CRITERIA FOR ES- TABLISHING CAUSATION}

Austin Bradford-Hill's criteria [89] are used to show whether an association is likely to be an causative relationship. He listed nine factors and all nine are met in the association between immunization and metabolic syndrome (Table 2). Austin Bradford-Hill analysis in part relies on bioplausibility. Based on the existing knowledge it is proposed that vaccines induce inflammation which increases cortisol or cortisol like activity leading to a Cushingoid like state which is metabolic syndrome.

\section{CLINICAL IMPLICATIONS FOR REVERSIBIL- ITY OF THE METABOLIC SYNDROME}

Current studies are being performed to try to reverse or prevent metabolic syndrome by decreasing cortisol activity. One approach is to inhibit the enzyme 11-beta hydroxysteroid dehydrogenase type 1 , an enzyme which increases the activity of cortisol in the peripheral tissue. Evidence from animal models of autoimmune disease suggests that suppression of cortisol, while likely to suppress metabolic syndrome, will increase the risk of autoimmune diseases. Decreasing cortisol production in rodents by adrenalectomy, for example, greatly increases the risk of diabetes in [86]. A safe and effective method of suppressing metabolic syndrome will require the reduction of inflammation, the precursor to both autoimmune disease and metabolic syndrome. Ideally one will want to reduce exposure to vaccines that lead to chronic inflammation. Once exposure to inflammatory mediators have been initiated, one can attempt to suppress the inflammation. There is evidence that certain anti-inflammatory agents will prevent development of metabolic syndrome. An anti-inflammatory drug AGI-1067 in its Phase III study called ARISE, showed a 64 percent reduction in patients developing diabetes in the group reviving AGI-1067 as compared to prospective controls.

\section{FUTURE STUDIES}

Vaccines continue to be approved based on small studies with only short term follow up. Theses studies are inade- 
quate to address safety issues such as metabolic syndrome [90]. Large prospective randomized clinical studies need to be performed to study the long term effects of specific vaccines on the risk of metabolic syndrome and its component diseases.

\section{Table 2. Austin Bradford-Hill Criteria For Establishing Cau- sation}

The nine criteria set by Austin Bradford-Hill for establishing causation are met with the association between vaccination and metabolic syndrome, supporting an causal relationship between vaccination and metabolic syndrome. The nine criteria are:

\section{Strength}

Answer: Yes. The association is strong and in children under 6 months of age the rise of obesity can not be explained by competing theories of poor diets and lack of exercise. The drop in type 2 diabetes in Japan following the discontinuation of BCG immunization is unprecedented. Only immunization has been published to cause such an effect on diabetes.

\section{Consistency}

Answer: Yes. The effect is consistent in different areas of the world including the US and Finland.

\section{Specificity}

Answer: Yes. Exposure to vaccines has been linked to immunological disorders and not to unrelated disorders.

\section{Temporality}

Answer: Yes. Children are immunized at 2 months of age and metabolic syndrome occurs later. The incidence of type 2 diabetes decreased after discontinuation of BCG vaccine in Japan.

\section{Biological Gradient}

Answer: Yes. There is a statistically significant correlation linking the number of vaccine doses to the prevalence of obesity.

\section{Plausibility}

Answer: Yes. The proposed mechanism has been described.

\section{Coherence}

Answer: Yes. There is an epidemic of obesity, hypertension, metabolic syndrome, type 2 diabetes and type 1 diabetes which increased with the increased number of vaccine doses recommended.

\section{Experimental Evidence}

Answer: Yes. Studies show increased inflammation and cortisol levels after immunization. An anti-inflammatory drug reduced the incidence of new cases of diabetes.

\section{Analogy}

Answer: Yes. The findings are analogous to vaccine induced type 1 diabetes.

\section{CONCLUSION}

There is an epidemic of metabolic syndrome and its components in children in the US. The epidemic of metabolic syndrome resembles the epidemic of type 1 diabetes in children which has been linked to vaccines. There is a statistically significant correlation between the prevalence of obesity and the number of vaccine doses recommended. A similar trend exists for hypertension, type 2 diabetes and metabolic syndrome. The data presented and prior publications indicates vaccine induce an immune spectrum disorder. One extreme of the disorder is the development of progressive autoimmune diseases such as type 1 diabetes. A second response to immunization, and an opposite extreme to autoimmunity, is for the body to suppress the immune system through increased cortisol activity and other counter measures leading to type 2 diabetes and metabolic syndrome. Some vaccine recipients may have a mixed response, falling between the extremes, such as an incomplete autoimmune disorder or an intermittent autoimmune disorder. The propensity to develop a particular response relates to race. The propensity to develop a particular response with racial differences. Japanese children produce larger amounts of cortisol following immunization and have a lower risk of type 1 diabetes but higher risk of type 2 diabetes than white children. Additional studies are needed to further characterize this risk.

\section{ACKNOWLEDGEMENT}

The author is president and share holder of Classen Immunotherapies. Classen Immunotherapies holds many patents and patent applications related to testing vaccines for their risk of chronic diseases including type 1 and type 2 diabetes.

\section{REFERENCES}

[1] Ford ES, Giles WH, Mokdad AH. Increasing prevalence of the metabolic dyndrome Among US adults. Diabetes Care 2004; 27: 2444-49.

[2] Duncan GE, Li SM, Zhou XH. Prevalence and trends of a metabolic syndrome phenotype among US adolescents, 1999-2000. Diabetes Care 2004; 27: 2438-43.

[3] Ford ES, Giles WH. A comparison of the prevalence of the metabolic syndrome using two proposed definitions. Diabetes Care 2003; $26: 575-81$.

[4] Lorenzo C, Okoloise M, Williams K, Stern MP, Haffner SM. The metabolic syndrome as a predictor of type 2 diabetes. Diabetes Care 2003; 26: 3153-59.

[5] Katzmarzyk PT, Church TS, Janssen I, Ross R, Blair SN. Metabolic syndrome. Obesity, and mortality. Diabetes Care 2005; 28: 391-97.

[6] Schulze MB, Hu FB. Dietary approaches to prevent the metabolic syndrome. Diabetes Care 2004; 27: 613-14.

[7] McAuley KA, Williams SM, Mann JI, et al. Intensive lifestyle changes are necessary to improve insulin sensitivity. Diabetes Care 2002; 25: 445-52.

[8] Kim J, Petersen KE, Scanlon KS, et al. Trends in overweight from 1980 through 2001 among preschool-aged children enrolled in a health maintenance organization. Obesity 2006; 14: 1107-12.

[9] Classen DC, Classen JB. The timing of pediatric immunization and the risk of insulin-dependent diabetes mellitus. Infect Dis Clin Pract 1997; 6: 449-54.

[10] Classen JB, Classen DC. Clustering of cases of IDDM occurring 2 4 years after vaccination is consistent with clustering after infections and progression to IDDM in autoantibody positive individuals. J Pediatr Endocrinol Metab 2003; 16: 495-508.

[11] Classen JB, Classen DC. Clustering of cases of insulin dependent diabetes [IDDM] occurring three years after Hemophilus influenza B [HiB] immunization support causal relationship between immunization and IDDM. Autoimmunity 2002; 35: 247-53.

[12] Classen JB, Classen DC. Vaccines and the risk of insulin dependent diabetes [IDDM], potential mechanism of action. Med Hypotheses 2001; 57: 532-38.

[13] Gherardi RK, Coquet M, Cherin P, et al. Macrophage myofasciitis lesions asses long-term persistence of vaccine-derived aluminum hydroxide in muscle. Brain 2001; 124: 1821-31.

[14] Oken E, Kasper DL, Gleason RE, Adler GK. Tetanus toxoid stimulation of the hypothalmic-pituitary-adrenal axis correlates inversely with the increase in tetanus toxoid antibody titers. J Clin Endocrinol Metab 1998; 83: 1691-96. 
[15] Catania A, Airaghi L, Manfredi G, Zanussi C. Hormonal responses during antigenic challenge in normal subjects. Int J Neurosci 1990; 51: 295-6.

[16] Gunnar MR, Brodersen L, Krueger K, Rigatuso J. Dampening of adrenocortical responses during infancy: Normative changes and individual differences. Child Dev 1996; 67: 877-89.

[17] Lewis M, Ramsay DS. Stress reactivity and self-recognition. Child Dev 1997; 68: 621-29.

[18] Ramsay D, Lewis M. Reactivity and regulation in cortisol and behavioral responses to stress. Child Dev 2003; 74: 456-64.

[19] Lewis M, Thomas D. Cortisol release in infants in response to inoculation. Child Dev 1990; 61: 50-59.

[20] Lewis M, Ramsay DS. Developmental changes in infants' responses to stress. Child Dev 1995; 66: 657-70.

[21] Ramsay DS, Lewis M. Developmental change in infant cortisol and behavioral response to inoculation. Child Dev 1994; 65: 1491-502.

[22] Duncan BB, Schmidt MI. Chronic activation of the innate immune system may underlie the metabolic syndrome. Sao Paulo Med J 2001; 119: 122-27.

[23] Laaksonen DE, Niskanen L, Nyyssonen K, et al. C-reactive protein and the development of metabolic syndrome and diabetes in middle age men. Diabetologia 2004; 47: 1403-10.

[24] Han TS, Sattar N, Williams K, Gonzalez-Villalpando C, Lean MEJ, Haffner SM. Prospective study of C-reactive protein in relation to the development of diabetes and metabolic syndrome in the Mexico City Diabetes Study. Diabetes Care 2002; 25: 2016-21.

[25] Wisse BE. The inflammatory syndrome: the role of adipose tissue cytokines in metabolic disorders linked to obesity. J Am S Nephrol 2004; 15: 2792-800.

[26] Pradhan AD, Manson JE, Rifa N, Buring JE, Ridker PM. Creactive protein, interleukin 6 , and risk of developing type 2 diabetes mellitus. JAMA 2001; 286: 327-34.

[27] Sesso HD, Buring JE, Rifai N, Blake GJ, Gaziano JM, Ridker PM. C-reactive protein and the risk of developing hypertension. JAMA 2003; 290: 2945-51.

[28] Vlachopoulos C, Dima I, Aznaouridis K, et al. Acute systemic inflammation increases arterial stiffness and decreases wave reflections in healthy individuals. Circulation 2005; 112: 2193-200.

[29] Visser M, Bouter LM, McQuillan GM, Wener MH, Harris TB. Low-grade systemic inflammation in overweight children. Pediatrics 2001; 107: e13-19.

[30] Karelis AD, Faraj M, Bastard JP, et al. The metabolically healthy but obese individuals presents a favorable inflammation profile. $\mathrm{J}$ Clin Endocrinol Metab 2005; 90: 4145-50.

[31] Bjorntorp P, Rosmond R. Hypothalmic origin of the metabolic syndrome X. Ann N Y Acad Sci 1999; 892: 297-307.

[32] Andrew R, Gale CR, Walker BR, Seck JR, Martyn CN. Glucocorticoid metabolism and the metabolic syndrome: Associations in an elderly population. Exp Clin Endocrinol Diabetes 2002; 110: 28490.

[33] Chiodini I, Torlontano M, Scillitani A, et al. Association of subclinical hypercorticolism with type 2 diabetes mellitus: case control study in hospitalized patients. Eur J Endocrinol 2005; 153: 837-44.

[34] O'Rhally SP. The metabolic syndrome: all in the mind? Diabet Med 1999; $16: 355-57$

[35] Bjorntorp P, Holm G, Rosmond R. Hypothalmic arousal, insulin resistance and type 2 diabetes mellitus. Diabet Med 1999; 16: 373 83.

[36] Brunner EJ, Hemingway H, Walker BR, et al. Adrenocortical, autonomic, and inflammatory causes of the metabolic syndrome: nested case control study. Circulation 2002; 106: 2659-65.

[37] Walker BR, Andrew R. Tissue production of cortisol by 11 beta hydroxy steroid dehydrogenase type 1 and metabolic disease. Ann N Y Acad Sci 2006; 1083: 165-84.

[38] Sandeep TC, Andrew R, Homer NZM, Andrews RC, Smith K, Walker BR. Increased in vivo regeneration of cortisol in adipose tissue in human obesity and effects of the 11 beta-hydroxysteroid dehydrogenase type 1 inhibitor carbenoxolone. Diabetes 2005; 54 : 872-79.

[39] Bahr V, Pfeiffer AF, Diederich S. The metabolic syndrome X and peripheral cortisol synthesis. Exp Clin Endocrinol Diabetes 2002; 110: 313-18

[40] Oltmanns KM, Dodt B, Schultes B, et al. Cortisol correlates with metabolic disturbances in a population study of diabetic patients. Eur J Endocrinol 2006; 154: 325-31.
[41] Walker BR, Soderberg S, Lindahl B, Olsson T. Independent effects of obesity and cortisol in predicting cardiovascular risk factors in men and women. J Intern Med 2000; 247: 198-204.

[42] Rosmond R, Bjorntorp P. The hypothalmic-pituitary-adrenal axis activity as a predictor of cardiovascular disease, type 2 diabetes and stroke. J Intern Med 2000; 247: 188-97.

[43] Esteve E, Ricart W, Fernadez-Real JM. Dyslipidemia and inflammation: an evolutionary conserved mechanism. Clin Nutr 2005; 24 16-31.

[44] Rowe J, Yerkovich ST, Richmond P, et al. Th-2 local reactions to the acellular diphtheria-tetanus-pertussis vaccine in 4 to 6 year old children. Infect Immun 2005; 73: 8130-35.

[45] Yousfi ME, Mercier S, Breuille D, et al. The inflammatory response to vaccination is altered in the elderly. Mech Ageing Dev 2005; 126: 874-81.

[46] Pourcyrous M, Korones SB, Crouse D, Bada HS. Interleukin-6, Creactive protein, and abnormal cardiorespiratory responses to immunization in premature infants. Pediatrics 1998; 101: e3-8.

[47] Bernstein ED, Gardner EM, Abrutyn E, Gross P, Murasko DM. Cytokine production after influenza vaccination in a healthy elderly population. Vaccine 1998; 16: 1722-31.

[48] Posthouwer D, Voorbij HAM, Grobbee DE, Numans ME, van der Bom JG. Influenza and pneumococcal vaccination as a model to assess C-reactive protein response to mild inflammation. Vaccine 2004; 23: 362-65.

[49] Authier FJ, Cherin P, Creange A, et al. Central nervous system disease in patients with macrophage myofasciitis. Brain $2001 ; 124$ : 974-83.

[50] Ershler WB, Sun WH, Binkley N, et al. Interleukin-6 and aging: blood levels and mononuclear cell production increase with advancing age and in vitro production is modifiable by dietary restriction. Lymphokine Cytokine Res 1993; 12: 225-30.

[51] Fagiolo U, Cossarizza A, Scala E, et al. Increased cytokine production in mononuclear cells in healthy elderly people. Eur J Immunol 1993; 23: 2375-78

[52] Roubenoff R, Harris TB, Abad LW, Wilson PW, Dallal GE, Dinarello $\mathrm{CA}$. Monocyte cytokine production in an elderly population: effect of age and inflammation. J Gerontol A Biol Sci Med Sci 1998; 53: M20-26.

[53] Rey AD, Klusman I, Besedovsky HO. Cytokines mediate protective stimulation of glucocorticoid output during autoimmunity, involvement of IL-1. Am J Physiol Regul Integr Comp Physiol 1998; 275: 1146-51.

[54] Angeli A, Masera RG, Sartori ML, et al. Modulation by cytokines of glucocorticoid action. Ann N Y Acad Sci 1999; 876: 210-20.

[55] Bethin KE, Voght SK, Muglia LJ. Interleukin-6 is an essential, corticotropin-releasing-hormone-independent stimulator of the adrenal axis during immune system activation. Proc Natl Acad Sci USA 2000; 97: 9317-22.

[56] Turnbull AV, Prehar S, Kennedy AR, Little RA, Hopkins SJ. Interleukin- 6 is an afferent signal to the hypothalmo-pituitary-adrenal axis during local inflammation in mice. Endocrinology 2003; 144: 1894-906.

[57] Vallieres L, Rivest S. Interleukin-6 is a needed proinflammatory cytokine in the prolonged neural activity and transcriptional activation of corticotropin-releasing factor during endotoxemia. Endocrinology 1999; 140: 3890-903.

[58] Pickup JC, Mattock MB, Chusney GD, Burt D. NIDDM as an disease of the innate immune system: association of acute-phase reactants and interleukin-6 with metabolic syndrome X. Diabetologia 1997 ; 40 : 1286-92.

[59] Hristova M, Aloe L. Metabolic syndrome, neurotrophic hypothesis. Med Hypotheses 2006; 66: 545-49.

[60] Senn JJ, Klover PJ, Nowak IA, Mooney RA. Interleukin-6 induces cellular insulin resistance in hepatocytes. Diabetes 2002; 51: 339199.

[61] Hall GV, Steensberg A, Sacchetti M, et al. Interleukin-6 stimulates lipolysis and fat oxidation in humans. J Clin Endocrinol Metab 2003; 88: 3005-10

[62] Nonogaki K, Fuller GM, Fuentes NL, et al. Interleukin-6 stimulates hepatic triglyceride secretion in rats. Endocrinology 1995; 136: 2143-49.

[63] Lyngso D, Simonsen L, Bulow J. Metabolic effects of interleukin-6 in splanchic and adipose tissue. J Clin Endocrinol Metab 2002; 543: $379-86$ 
[64] Levitt NS, Lambert EV, Woods D, Hales N, Andrew R, Seckl J. Impaired glucose tolerance and impaired blood pressure in low birth weight, non obese, young South African adults: early programing of the cortisol axis. J Clin Endocrinol Metab 2000; 85: 4611-18.

[65] Phillips DIW, Barker DJP, Fall CHD, et al. Elevated plasma cortisol concentrations: a link between low birth weight and insulin resistance syndrome. J Clin Endocrinol Metab 1998; 83: 757-60.

[66] Seckl JR, Meaney MJ. Glucocorticoid programming. Ann N Y Acad Sci 2004; 1032: 63-8.

[67] Boney CM, Verma A, Tucker R, Vohr BR. Metabolic syndrome in childhood: association with birth weight, maternal obesity, and gestational diabetes mellitus. Pediatrics 2005; 115: 290-6.

[68] Haines L, Wan KC, Lynn R, Barrett TG, Shield JPH. Rising incidence of type 2 diabetes in children in the UK. Diabetes Care 2007; 30: 1097-101.

[69] McMahon SK, Haynes A, Ratnan N, et al. Increase in type 2 diabetes in children and adolescents in Western Australia. Med J Aust 2004; 180: 459-61.

[70] Strauss RS, Pollack HA. Epidemic increase in childhood overweight, 1986-1998. JAMA 2001; 286: 2845-48.

[71] Troiano RP, Flegal KM. Overweight children and adolescents: description, epidemiology, and demographics. Pediatrics 1998; 101: 497-504.

[72] Ogden CL, Flegal KM, Carroll MD, Johnson CL. Prevalence and trends in overweight among US children and adolescents, 19992000. JAMA 2002; 288: 1728-32.

[73] Muntner P, He J, Cutler JA, Wildman RP, Whelton PK. Trends in blood pressure among children and adolescents. JAMA 2004; 291: 2107-13.

[74] Vehik K, Hamman RF, Lezotte D, et al. Increasing incidence of type 1 diabetes in 0 to 17 year old Colorado youth. Diabetes Care 2007; 30: 503-9.

[75] Kautiainen S, Rimpela A, Vikat A, Viratanen SM. Secular trends in overweight and obesity among Finnish adolescents in 1977-1999. Int J Obes Metab Disord 2002; 26: 544-52.

[76] Tuomilehto J, Karvonen M, Pitkaniemi J, et al. Record high incidence of type 1 [insulin dependent] diabetes mellitus in Finnish children. Diabetologia 1999; 42: 655-60.

[77] Pinhas-Hamiel O, Zeitler P. The global spread of type 2 diabetes mellitus in children and adolescents. J Pediatr 2005; 146: 693-700.
[78] Urakami T, Morimoto S, Nitadori Y, Harada K, Owada M, Kitagawa $T$. Recent change in the annual incidence of childhood type 2 diabetes in the Tokyo metropolitan area. Clin Pediatr Endocrinol 2007; $16: 53-8$.

[79] Urakami T, Owada M, Kitagawa T. Recent trend toward the decrease in the incidence of type 2 diabetes in Tokyo. Diabetes Care 2006; 29: 2176-7.

[80] Classen JB. Discontinuation of BCG vaccination precedes significant drop in Type 2 Diabetes in Japanese children. Role of inflammation and cortisol activity as a cause of Type 2 diabetes. Open Endocrinol J 2008; 2: 1-4.

[81] Ogawa Y, Uchigata Y, Otani T, Iwamoto Y. Proportion of diabetes type in Early-Onset Diabetes in Japan. Diabetes Care 2007; 30: e30.

[82] Dabela D. Incidence of diabetes in youth in the United States. JAMA 2007; 297: 2716-24.

[83] Onkamo P, Vaananen S, Karvonen M, Tuomilehto J. Worldwide increase in the incidence of type 1 diabetes-the analysis of the data on published incidence trends. Diabetologia 1999; 42: 1395-403.

[84] Lewis M, Ramsay DS, Kawakami K. Differences between Japanese infants and caucasian American infants in Behavioral and cortisol response to inoculation. Child Dev 1993; 64: 1722-31.

[85] Ward AMV, Fall CHD, Stein CE, et al. Cortisol and the metabolic syndrome in South Asians. Clin Endocrinol 2003; 58: 500-5.

[86] Saravia-Fernadez F, Durant S, el Hasnaoui A, Dardenne M, HomoDelarche F. Environmental and experimental procedures leading to variations in the incidence of diabetes in the nonobese diabetic [NOD] mice. Autoimmunity 1996; 24: 113-21.

[87] Bolton C, O'Neill JK, Allen SJ, Baker D. Regulation of chronic relapsing experimental allergic encephalomyelitis by endogenous and exogenous glucocorticoids. Int Arch Allergy Immunol 1997; 114: 74-80.

[88] Peers DH, Duncan GS, Flower RJ, Bolton C. Endogenous corticosteroids modulate proliferation and susceptibility to experimental allergic encephalomyelitis in the Brown Norway rat. Int Arch Allergy Immunol 1995; 106: 20-4.

[89] Hill AB. The environment and disease, association or causation. Proc R Soc Med 1965; 58: 295-300.

[90] Ellenberg SS, Foulkes MA, Midthun K, Goldenthal KL. Evaluating the safety of new vaccines:summary of a workshop. Am J Public Health 2005; 95: 800-7.

(C) John Barthelow Classen; Licensee Bentham Open.

This is an open access article licensed under the terms of the Creative Commons Attribution Non-Commercial License (http://creativecommons.org/licenses/by$\mathrm{nc} / 3.0 /$ ) which permits unrestricted, non-commercial use, distribution and reproduction in any medium, provided the work is properly cited. 